\title{
Rehabilitation and Return to Sport Testing After Anterior Cruciate Ligament Reconstruction: Where Are We in 2022?
}

\author{
Alli Gokeler, Ph.D., P.T., Bart Dingenen, Ph.D., P.T., and Timothy E. Hewett, Ph.D.
}

\begin{abstract}
Athletes who sustain an anterior cruciate ligament (ACL) injury often opt for an ACL reconstruction (ACLR) with the goal and expectation to return to sports at the preinjury level. The proportion of athletes who successfully return to preinjury-level sport is low and disappointing, whereas the rate of second ACL injury in athletes under the age of 20 has been reported to be as high as $40 \%$ after return to sport (RTS). Although in recent years, new insights pertaining to RTS have been published, the lack of validity of RTS criteria after ACLR remain. The purpose of this clinical commentary is to present a critical overview of the current literature on RTS testing after ACLR.
\end{abstract}

\begin{abstract}
A $n$ injury of the anterior cruciate ligament (ACL) is a common injury in athletes participating in landing- and pivoting-type sports. An ACL reconstruction (ACLR) is considered by many the clinical standard to restore mechanical stability of the joint as a prerequisite for return to sports (RTS). ${ }^{1}$ Webster and Feller ${ }^{2}$ recently determined that patients who were about to undergo a primary ACLR had high expectations for return to their preinjury level of sport, with $88 \%$ expecting to achieve this outcome. In reality, only $65 \%$ of patients after ACLR return to their preinjury level of sport. $^{3}$ Unfortunately, the active, young athlete $(<20$ years) who resumes activity after ACLR has a greater risk for a second ACL injury. Injury rates in this young
\end{abstract}

From the OCON Centre of Orthopaedic Surgery and Sports Medicine (A.G.), Hengelo, The Netherlands; the Exercise Science and Neuroscience Unit, Department Exercise $\theta$ Health, Faculty of Science, University of Paderborn (A.G.), Paderborn, Germany; Reval Rehabilitation Research Center, Faculty of Rehabilitation Sciences, Hasselt University (B.D.), Diepenbeek, Belgium; Hewett Global Consultants (T.E.H.), Rochester, Minnesota; and the Rocky Mountain Consortium for Sports Research (T.E.H.), Edwards, Colorado, U.S.A.

The authors report that they have no conflicts of interest in the authorship and publication of this article. Full ICMJE author disclosure forms are available for this article online, as supplementary material.

Received October 9, 2021; accepted October 30, 2021.

Address correspondence to Alli Gokeler, Ph.D., P.T., OCON Centre of Orthopaedic Surgery and Sports Medicine, Geerdinksweg 141, Hengelo, The Netherlands.E-mail: a.gokeler@ocon.nl

(C) 2021 THE AUTHORS. Published by Elsevier Inc. on behalf of the Arthroscopy Association of North America. This is an open access article under the CC BY-NC-ND license (http://creativecommons.org/licenses/by-nc-nd/4.0/).

2666-061X/211472

https://doi.org/10.1016/j.asmr.2021.10.025 cohort have been reported to be up to $23 \%$ to $29 \%$ in the literature. ${ }^{4-6}$ In men's Australian football, second ACL injury rates of $40 \%$ after RTS have recently been reported.

There has consequently been a growth in studies that propose RTS criteria with the aim to reduce the risk of a second ACL injury. Despite the development of RTS guidelines over recent years, there is a lack of a scientific consensus on the RTS criteria used to release a patient to unrestricted sport activity after ACLR. ${ }^{8}$ A proportional meta-analysis showed that only $23 \%$ of patients after ACLR passed RTS test batteries before RTS. ${ }^{9}$ These findings highlight that many patients may have returned to sport without acceptable knee function. Although passing RTS criteria reduce the risk of subsequent graft rupture by $60 \%$, it increases the risk of a contralateral ACL rupture by $235 \%$. ${ }^{9}$ In support of this meta-analysis, a recent study found that RTS tests including strength, hop tests, and patient-reported outcomes fail to identify patients who are at risk for a second ACL injury. ${ }^{10}$

Overall, the validity of current RTS tests is questionable. These equivocal findings in terms of validity of RTS tests after ACLR leaves clinicians with high level of uncertainty in clinical decision-making. The purpose of this clinical commentary is to present a critical overview of the current literature on RTS testing after ACLR.

\section{Definition of RTS tests}

Although the specific content of reported RTS test batteries has varied, overall they are designed to incorporate several domains of risk factors. An RTS test 
battery should at least include strength tests, hop tests, and measures of quality of movement. ${ }^{11}$ More recently, the importance of athletes' psychological responses to the initial injury, to surgery, and to recovery during rehabilitation are important additional determinants of RTS. ${ }^{12}$ In the following sections we will discuss the various components that compromise the current recommended RTS test battery.

\section{Muscle Strength}

In the United States, $56 \%$ of therapists use manual muscle testing as their only method of strength evaluation. ${ }^{13}$ This is an area of concern because manual muscle tests using the Medical Research Council scale has several limitations, including poorly defined limits between grades " 4 " and " 5. ." 14 For research purposes, isokinetic dynamometry is often used for strength assessment of the quadriceps and hamstrings. ${ }^{15}$ However, isokinetic devices lack practicality in clinical settings because of high cost, lack of portability, and space requirements. A more clinically viable alternative is hand-held dynamometry ${ }^{16}$ or the use of, for example, a leg press or leg extension machine. ${ }^{17}$

Commonly a limb symmetry index (LSI) is used, defined as the ratio of the involved limb score and the uninvolved limb score expressed in percent ((involved/ uninvolved) - 100). An LSI $>90 \%$ is usually used as a cutoff score. ${ }^{18}$ For recreational and non-pivoting sports an LSI of $>90 \%$ may be acceptable, whereas a $>100 \%$ LSI for knee extensor and knee flexor muscle strength for the pivoting/contact/competitive athlete has been recommended. ${ }^{19} \mathrm{~A}$ few major issues arise when using these criteria: 1) only $14 \%$ of all patients achieved a LSI of $100 \%$ for strength tests at 2 years after ACLR $^{20}$ questioning whether this is feasible in daily practice; 2 ) the LSI is based on the assumption that the uninjured leg can be used as a reference for strength. Larsen et al. ${ }^{21}$ showed that, not only do patients after ACLR exhibit side to side deficits, but the uninvolved limb of ACLR is also significantly weaker to a matched limb of a control group. This implies that the LSI may underestimate strength deficits and argues for an implementation of absolute strength evaluation and not only limb symmetry. ${ }^{21}$ Current evidence summarized in a metaanalysis revealed persistent quadriceps and hamstring strength deficits in both the short ( $<6$ months) and long term ( $>2$ years) after ACL injury. ${ }^{22}$ In that metaanalysis, studies comparing the strength on the involved side with the uninvolved side were excluded because there was evidence of bilateral neuromuscular changes after unilateral injury. ${ }^{22}$

Most studies report assessment of maximal strength; however, this may only present the tip of the iceberg of strength deficits after ACLR. Deficits in rate of force development, power, and reactive strength have been reported as well, which may have important relationships with athletic performance and second ACL injury prevention rather than maximal strength alone. ${ }^{23}$

\section{Hop Tests}

Commonly used hop tests are the single hop for distance, triple hop for distance, triple cross-over hop, and the 6-m timed hop. ${ }^{24}$ LSI criteria $>90 \%$ could be used as cutoff scores to determine readiness for RTS in recreational or nonpivoting-type sports, whereas an LSI of $100 \%$ is recommended for pivoting/contact sports. ${ }^{19}$ As with the LSI for strength, there are some concerns regarding the use of the uninvolved limb as a reference for the involved limb. Athletes who have undergone an ACLR demonstrate bilateral deficits on hop tests in comparison to age- and sex-matched normative data of healthy controls. ${ }^{25}$ Of interest, all athletes in that study had a mean LSI of $95.4 \%$ for the 3 hop tests, being well over the clinical cutoff of $90 \%$ symmetry frequently used for RTS criteria. ${ }^{25}$ Despite achieving an LSI $>90 \%$, patients demonstrated significant and clinical relevant deficits in performance for both limbs when compared to normative data from healthy athletes. Findings from a recent meta-analysis suggest that symmetry in hop distance may not mean knee function is also symmetrical. ${ }^{26}$ Moreover, the LSI should not be used in isolation to evaluate functional performance changes after ACLR, because it may overestimate functional improvement, as a result of worsening contralateral limb function. ${ }^{27}$ Using the LSI for hop tests may underestimate performance deficits and should therefore be used with caution as a criterion for RTS after ACLR. ${ }^{25,28,29}$ On a final note, a limitation of the current hop test battery is that these tests predominantly consist of straight movements in the forward direction. Medial and rotational hop tests are more likely to show limb asymmetries in athletes after ACLR participants compared to forward hop tests. ${ }^{30}$

\section{Movement Quality Assessment}

Although patients after ACLR may achieve normalization in single leg hop test distance, kinematic and kinetic deficits may persist. ${ }^{29}$ Welling et al. ${ }^{31}$ found that $60 \%$ of patients after ACLR had abnormal landing kinematics in the injured leg compared to their noninjured leg, although $72.3 \%$ of them passed the LSI $>90 \%$ criteria for hop tests. Between-limb deficits in eccentric and concentric loading parameters persist $>9$ months after ACLR, indicating a compensatory offloading strategy to protect the involved limb during an athletic performance task. ${ }^{32}$ In addition, graft-specific loading asymmetries have been identified for double leg jump-landing tasks. ${ }^{33}$ Greater asymmetry of trunk-side flexion, distance from center of mass to the knee and ankle in the frontal plane, pelvic tilt, and pelvic drop during unplanned change of direction was found for those athletes who sustained second ACL injuries 
compared to this who did not. ${ }^{34}$ Therefore the integration of a biomechanical evaluation should supplement the decision-making regarding RTS.

\section{Psychological factors}

An ACL injury not only leads to physical impairments but also has a psychological impact. Hence, in addition to the physical readiness, monitoring patient-reported outcome measures and psychological readiness are important to determine successful RTS. Significantly lower scores on self-reported knee function questionnaires were found in patients who did not RTS compared to patients who RTS. ${ }^{35}$ Psychological readiness is a predictor for returning to preinjury levels of sport in patients after ACLR. ${ }^{36}$

A systematic review revealed that $65 \%$ of patients cited a psychological reason for not returning to sport, with fear of reinjury as the most common reason. ${ }^{37}$ In other words, patients with higher scores on questionnaires regarding psychological readiness for RTS had increased chances to return to the preinjury level of sport.

\section{Rehabilitative Approach}

RTS tests should be seen in the context of factors such as content, specificity, intensity, frequency, and duration of rehabilitation given the need for optimization of current rehabilitation programs. Several conceptual frameworks on how rehabilitation can be optimized have been published but require scientific validation. ${ }^{8,38,39}$ In a retrospective study of 676 patients after ACLR, an individualized RTS rehabilitation program supervised by strength and conditioning coaches over a period of 3 months in addition to the standard rehabilitation program was the most important factor to positively influence an RTS test battery. ${ }^{40}$ This study is in agreement with previous studies. ${ }^{41,42}$ Patients who completed 6 months of rehabilitation incorporating jumping and agility tasks were almost 8 times more likely to RTS compared with those who did not. ${ }^{41}$ Della Villa et al. $^{42}$ evaluated the association between compliance in postoperative rehabilitation and RTS rate in patients after ACLR revision. As much as $86 \%$ of fully compliant patients were able to return to the preinjury level, versus $50 \%$ and $45 \%$ of the patients defined as minimally compliant and noncompliant, respectively. ${ }^{42}$

\section{Timing of RTS testing?}

It has been suggested to delay RTS until 9 months after ACLR surgery. ${ }^{43}$ However, the claimed $84 \%$ reduction of risk was a nonsignificant finding because of low statistical power. ${ }^{43}$ Between 9 months and 2 years after surgery, there was no significant reduction in the risk for second knee injuries. Over that time period, $19.4 \%$ of these patients sustained second knee reinjuries. $^{43}$
In a recent study no clear association between age and second ACL injury was suggested. ${ }^{44}$ This is in conflict with other studies. Webster et al. ${ }^{5}$ reviewed 561 patients at a mean follow-up of approximately 5 years and reported odds for sustaining a contralateral ACL rupture increased threefold for patients younger than 20 years. Kaeding et al. ${ }^{45}$ reviewed 2683 patients from the Multicenter Orthopaedic Outcomes Network cohort and reported that younger age and higher activity level (and allograft type) were predictors of increased odds of ipsilateral graft failure. It may be questioned whether young age is indeed a risk factor or a proxy for higher exposure to high-risk activities such as return to soccer or other landing and pivoting sports.

Future studies should clearly point out whether tests were conducted at a certain fixed time point (for example 9 months after surgery) or at the time of return to sport. If the second option would be the case, it should be clear which criteria were used to decide whether it's safe to return to sport.

\section{How Many Tests Need to Be Included?}

Another problem with these test batteries is the "penalty" of multiple tests. With a test battery, multiple tests across several domains are required to be passed at a required pass rate, which was most often set at $90 \%$. If athletes meet the pass rate for one test and a second test with a $90 \%$ pass requirement is added, the percentage of athletes who pass will almost certainly drop. ${ }^{46}$ For example, even if $80 \%$ of athletes pass each test of a test battery, the overall pass rate for the test battery will be dependent on the total number of tests such that the pass rate for the first test will be $80 \%$, but then only $64 \%(0.8 \times 0.8)$ for 2 tests, $51 \%(0.64 \times 0.8)$ for $3,40 \%(0.5 \times 0.8)$ for 4 , and so on ${ }^{47}$ Furthermore, the relative importance of each of these tests is unknown and can vary between sports and individuals.

\section{What Are the Consequences of the RTS Testing?}

The consequence of not passing tests, is often not explicitly stated in studies. In the study of Grindem et al., $^{43}$ of the 74 patients who returned to level 1 sports, those 51 patients who did not sustain a second knee injury had a mean quadriceps LSI of $84.4 \%$, which was below the recommended LSI of $>90 \%$. In the review of Webster and Hewett, ${ }^{9} 77 \%$ of patients who did not pass RTS test after ACLR, participated in sports. On the one hand, the above findings highlight the need for a stricter definition of what the consequences of the tests are. On the other hand, the very low proportion of athletes passing the traditional RTS tests also indicate that in general, a criterion-based rehabilitation is not adopted in clinical practice. ${ }^{13,48,49}$

The problem within the current literature is that we hardly know what happened after the RTS tests. The exposure to high-risk activities is an essential point 
when evaluating the validity of RTS tests. Indeed, a player failing RTS tests but returning to sports with very low exposure to high-risk activities might still be at a relatively lower injury risk compared to another player passing RTS tests with very high exposure to high-risk activities. However, this exposure is not reported in current studies. The use of the term RTS must be accompanied by a detailed description of the individual characteristics of the athletes being studied; the intensity, duration, and frequency of each exposure; duration of sport participation after ACLR; the type and level of activity; and the use of protective equipment. ${ }^{8}$ Truly successful RTS allows the athlete to return to their prior level of sport while also at a reduced (or reasonable) risk for a second ACL (or any) injury.

\section{Conclusion}

After ACLR, ligament (ACL), the proportion of athletes who successfully return to pre-injury level sport is low and disappointing, while the rate of second ACL injury in athletes under the age of 20 has been reported to be as high as $40 \%$ after RTS. Although in recent years, new insights pertaining RTS have been published, the lack of validity of RTS criteria after ACLR remains.

\section{References}

1. Marx RG, Jones EC, Angel M, Wickiewicz TL, Warren RF. Beliefs and attitudes of members of the American Academy of Orthopaedic Surgeons regarding the treatment of anterior cruciate ligament injury. Arthroscopy 2003;19: 762-770.

2. Webster KE, Feller JA. Expectations for return to preinjury sport before and after anterior cruciate ligament reconstruction. Am J Sports Med 2019;47:578-583. doi:10. $1177 / 0363546518819454$.

3. Ardern CL, Taylor NF, Feller JA, Webster KE. Fifty-five per cent return to competitive sport following anterior cruciate ligament reconstruction surgery: An updated systematic review and meta-analysis including aspects of physical functioning and contextual factors. Br J Sport Med 2014;48:1543-1552.

4. Paterno MV, Rauh MJ, Schmitt LC, Ford KR, Hewett TE. Incidence of second ACL injuries 2 years after primary ACL reconstruction and return to sport. Am J Sports Med 2014;42:1567-1573.

5. Webster KE, Feller JA, Leigh WB, Richmond AK. Younger patients are at increased risk for graft rupture and contralateral injury after anterior cruciate ligament reconstruction. Am J Sport Med 2014;42:641-647.

6. Webster KE, Feller JA. Exploring the high reinjury rate in younger patients undergoing anterior cruciate ligament reconstruction. Am J Sport Med 2016;44:2827-2832.

7. Webster KE, Hewett TE, Feller JA. Anterior cruciate ligament injuries in Australian rules football: Incidence, prevention and return to play outcomes. Open Access $J$ Sport Med 2021;12:33-41.
8. Dingenen B, Gokeler A. Optimization of the return-tosport paradigm after anterior cruciate ligament reconstruction: A critical step back to move forward. Sport Med 2017;47:1487-1500.

9. Webster KE, Hewett TE. What is the evidence for and validity of return-to-sport testing after anterior cruciate ligament reconstruction surgery? A systematic review and meta-analysis. Sport Med 2019;49:917-929.

10. Welling W, Benjaminse A, Lemmink K, Gokeler A. Passing return to sports tests after ACL reconstruction is associated with greater likelihood for return to sport but fail to identify second injury risk. Knee 2020;27:949-957.

11. van Melick N, van Cingel RE, Brooijmans F, et al. Evidence-based clinical practice update: Practice guidelines for anterior cruciate ligament rehabilitation based on a systematic review and multidisciplinary consensus. $\mathrm{Br} J$ Sport Med 2016;50:1506-1515.

12. Truong LK, Mosewich AD, Holt CJ, Le CY, Miciak M, Whittaker JL. Psychological, social and contextual factors across recovery stages following a sport-related knee injury: A scoping review. Br J Sports Med 2020;54: 1149-1156.

13. Greenberg EM, Greenberg ET, Albaugh J, Storey E, Ganley TJ. Rehabilitation practice patterns following anterior cruciate ligament reconstruction: A survey of physical therapists. J Orthop Sport Phys Ther 2018;48:801-811.

14. O'Neill S, Jaszczak SLT, Steffensen AKS, Debrabant B. Using $4+$ to grade near-normal muscle strength does not improve agreement. Chiropr Man Ther 2017;25:1-9.

15. Logerstedt DS, Snyder-Mackler L, Ritter RC, Axe MJ, Godges JJ. Knee stability and movement coordination impairments: Knee ligament sprain. J Orthop Sport Phys Ther 2010;40:A1-A37.

16. Kim S-G, Lee Y-S. The intra- and inter-rater reliabilities of lower extremity muscle strength assessment of healthy adults using a hand held dynamometer. J Phys Ther Sci 2015;27:1799-1801.

17. Nagai T, Schilaty ND, Laskowski ER, Hewett TE. Hop tests can result in higher limb symmetry index values than isokinetic strength and leg press tests in patients following ACL reconstruction. Knee Surgery, Sport Traumatol Arthrosc 2020;28:816-822.

18. Lynch AD, Logerstedt DS, Grindem H, et al. Consensus criteria for defining "successful outcome" after ACL injury and reconstruction: A Delaware-Oslo ACL cohort investigation. Br J Sport Med 2015;49:335-342.

19. Thomeé R, Kaplan Y, Kvist J, et al. Muscle strength and hop performance criteria prior to return to sports after ACL reconstruction. Knee Surgery, Sport Traumatol Arthrose $2011 ; 19: 1798-1805$.

20. Thomeé R, Neeter C, Gustavsson A, et al. Variability in leg muscle power and hop performance after anterior cruciate ligament reconstruction. Knee Surgery, Sport Traumatol Arthrosc 2012;20:1143-1151.

21. Larsen JB, Farup J, Lind M, Dalgas U. Muscle strength and functional performance is markedly impaired at the recommended time point for sport return after anterior cruciate ligament reconstruction in recreational athletes. Hum Mov Sci 2015;39:73-87.

22. Tayfur B, Charuphongsa C, Morrissey D, Miller SC. Neuromuscular function of the knee joint following knee 
injuries: Does it ever get back to normal? A systematic review with meta-analyses. Sport Med 2021;51:321-338.

23. Maestroni L, Read P, Turner A, Korakakis V, Papadopoulos K. Strength, rate of force development, power and reactive strength in adult male athletic populations post anterior cruciate ligament reconstruction-A systematic review and meta-analysis. Phys Ther Sport 2021;47:91-104.

24. Logerstedt DS, Scalzitti D, Risberg MA, et al. Knee stability and movement coordination impairments: Knee ligament sprain revision 2017. J Orthop Sport Phys Ther 2017;47: Al-A47.

25. Gokeler A, Welling W, Benjaminse A, Lemmink K, Seil R, Zaffagnini S. A critical analysis of limb symmetry indices of hop tests in athletes after anterior cruciate ligament reconstruction: A case control study. Orthop Traumatol Surg Res 2017;103:947-951.

26. Kotsifaki A, Whiteley R, Van Rossom S, et al. Single leg hop for distance symmetry masks lower limb biomechanics: Time to discuss hop distance as decision criterion for return to sport after ACL reconstruction? [published online March 9, 2021]. Br J Sports Med, https://doi.org/ 10.1136/bjsports-2020-103677.

27. Patterson BE, Crossley KM, Perraton LG, et al. Limb symmetry index on a functional test battery improves between one and five years after anterior cruciate ligament reconstruction, primarily due to worsening contralateral limb function. Phys Ther Sport 2020;44:67-74.

28. Wellsandt E, Failla MJ, Snyder-Mackler L. Limb symmetry indexes can overestimate knee function after anterior cruciate ligament injury. J Orthop Sport Phys Ther 2017: $1-18$.

29. Kotsifaki A, Korakakis V, Whiteley R, Van Rossom S, Jonkers I. Measuring only hop distance during single leg hop testing is insufficient to detect deficits in knee function after ACL reconstruction: A systematic review and meta-analysis. Br J Sports Med 2020;54:139-153.

30. Dingenen B, Truijen J, Bellemans J, Gokeler A. Test-retest reliability and discriminative ability of forward, medial and rotational single-leg hop tests. Knee 2019;26:978-987.

31. Welling W, Benjaminse A, Seil R, Lemmink K, Gokeler A. Altered movement during single leg hop test after ACL reconstruction: Implications to incorporate 2-D video movement analysis for hop tests. Knee Surg Sport Traumatol Arthrosc 2018;26:3012-3019.

32. Read PJ, Michael Auliffe S, Wilson MG, Graham-Smith P. Lower limb kinetic asymmetries in professional soccer players with and without anterior cruciate ligament reconstruction: Nine months is not enough time to restore "functional" symmetry or return to performance. Am J Sports Med 2020;48:1365-1373.

33. Miles JJ, King E, Falvey ÉC, Daniels KAJ. Patellar and hamstring autografts are associated with different jump task loading asymmetries after ACL reconstruction. Scand J Med Sci Sport 2019;29:1212-1222.

34. King E, Richter C, Daniels KAJ, et al. Biomechanical but not strength or performance measures differentiate male athletes who experience ACL reinjury on return to level 1 sports. Am J Sports Med 2021;49:918-927.
35. Ardern CL, Taylor NF, Feller JA, Whitehead TS, Webster KE. Sports participation 2 years after anterior cruciate ligament reconstruction in athletes who had not returned to sport at 1 year: A prospective follow-up of physical function and psychological factors in 122 athletes. Am J Sport Med 2015;43:848-856.

36. Ardern CL, Taylor NF, Feller JA, Whitehead TS, Webster KE. Psychological responses matter in returning to preinjury level of sport after anterior cruciate ligament reconstruction surgery. Am J Sport Med 2013;41: 1549-1558.

37. Nwachukwu BU, Adjei J, Rauck RC, et al. How much do psychological factors affect lack of return to play after anterior cruciate ligament reconstruction? A systematic review. Orthop J Sport Med 2019;7:1-7.

38. Gokeler A, Benjaminse A, Hewett TE, et al. Feedback techniques to target functional deficits following anterior cruciate ligament reconstruction: Implications for motor control and reduction of second injury risk. Sport Med 2013;43:1065-1074.

39. Gokeler A, Neuhaus D, Benjaminse A, Grooms DR, Baumeister J. Principles of motor learning to support neuroplasticity after ACL injury: Implications for optimizing performance and reducing risk of second ACL injury. Sport Med 2019;49:853-865.

40. Franck F, Saithna A, Vieira TD, et al. Return to sport composite test after anterior cruciate ligament reconstruction (K-STARTS): Factors affecting return to sport test score in a retrospective analysis of 676 patients. Sport Health 2021;13:364-372.

41. Edwards PK, Ebert JR, Joss B, et al. Patient characteristics and predictors of return to sport at 12 months after anterior cruciate ligament reconstruction: The importance of patient age and postoperative rehabilitation. Orthop $J$ Sport Med 2018;6:232596711879757.

42. Della Villa F, Andriolo L, Ricci M, et al. Compliance in post-operative rehabilitation is a key factor for return to sport after revision anterior cruciate ligament reconstruction. Knee Surg Sport Traumatol Arthrosc 2020;28: 463-469.

43. Grindem H, Snyder-Mackler L, Moksnes H, Engebretsen L, Risberg MA. Simple decision rules can reduce reinjury risk by $84 \%$ after ACL reconstruction: The Delaware-Oslo ACL cohort study. Br J Sports Med 2016;50: 804-808.

44. Grindem H, Engebretsen L, Axe M, Snyder-Mackler L, Risberg MA. Activity and functional readiness, not age, are the critical factors for second anterior cruciate ligament injury-The Delaware-Oslo ACL cohort study. Br J Sports Med 2020;54:1099-1102.

45. Kaeding CC, Pedroza AD, Reinke EK, et al. Risk factors and predictors of subsequent ACL injury in either knee after ACL reconstruction. Am J Sports Med 2015;43: 1583-1590.

46. Toole AR, Ithurburn MP, Rauh MJ, Hewett TE, Paterno MV, Schmitt LC. Young athletes after anterior cruciate ligament reconstruction cleared for sports participation: How many actually meet recommended return-to-sport criteria cutoffs? J Orthop Sport Phys Ther 2017;47:1-27. 
47. Hewett TE, Webster KE, Hurd WJ. Systematic selection of key logistic regression variables for risk prediction analyses: A five-factor maximum model. Clin J Sport Med 2019;29:78-85.

48. Ebert JR, Webster KE, Edwards PK, et al. Current perspectives of Australian therapists on rehabilitation and return to sport after anterior cruciate ligament reconstruction: A survey. Phys Ther Sport 2019;35: 139- 145 .

49. Dingenen B, Billiet B, De Baets L, Bellemans J, Truijen J, Gokeler A. Rehabilitation strategies of Flemish physical therapists before and after anterior cruciate ligament reconstruction: An online survey. Phys Ther Sport 202 1;49: 68-76. 